\title{
4C THE EUROPEAN TELECOMMUNICATIONS SATELLITE ORGANIZATION
}

\author{
Andrea Caruso, Secretary General, Eutelsat
}

Other satellite communication systems have been established for the purpose of providing telecommunications services between areas where such services were non-existent or totally insufficient. The Eutelsat system, however, was not originally conceived to fill telecommunications gaps. In view of the extensive European terrestrial network already in place, the objectives of the system are to satisfy specific European telecommunications requirements and to enable the European aerospace industry to develop a full range of technologies so that it may compete in the world market. Therefore, it is essential that Eutelsat be as economically efficient as possible in order to provide a financial advantage over the terrestrial network.

The Eutelsat system basically provides services which are not available via Intelsat in Europe. However, it is important to point out that the European PTT's and their governments sought full coordination under Article XIV of the Intelsat Agreement, from both technical and economic points of view, before taking any steps to establish Eutelsat. Today, Eutelsat complements the already well-developed European terrestrial network, but does not provide any television circuits outside the European broadcasting zone.

Eutelsat provides the following services: 1) it channels a significant portion of intra-European public telephone traffic, 2) it leases portions of the space segment for the distribution of television programmes, 3) it provides multi-service transmissions tailored to the specific needs of the business community, and 4) provides for the transmission of Eurovision television programmes.

Eutelsat provides reliable voice telecommunications services to its member administrations, enabling them to make better use of existing terrestrial facilities by allowing overcrowded major European paths to be off-loaded and transit problems to be overcome. With 12 television programmes currently being transmitted to 18 countries, Eutelsat has strengthened national cable TV policies by making a large number of varied, high-quality European programmes available to cable operators. In addition, European business companies can now benefit from flexible, easily implemented digital links.

Eutelsat I-F1 has been operating at full load since the beginning of its operational life in October 1983, while the F2 satellite, successfully launched in August 1984, is fulfilling its mission as the main operational satellite. In response to the demand for additional fixed satellite service in Europe, Eutelsat has decided to add a third operational satellite. Eutelsat's space segment is fully coordinated by the European Space Agency, which procures spacecraft from European manufacturers. In addition, all satellites are launched by the European launcher, Ariane.

\section{FUTURE PLANS}

Eutelsat will continue to stimulate and serve that part of the telecommunications business where the use of a satellite network is of particular benefit. Eutelsat thus enables the member PTT administrations to secure optimum economic distribution between the various terrestrial systems and satellite transmission capacity.

The great success of the Eutelsat I satellites has led the way, and the study and procurement process for the second generation of Eutelsat satellites is now well under way. Three flight units will be involved, the first launch is scheduled for mid-1989 and Eutelsat has an option on two additional units. Technological improvements to this new generation will include enhanced coverage of the service zones by means of shaped-beam antennas, greater operational flexibility for the transponders, and a number of improvements to the transponders' basic characteristics.

Eutelsat will also continue to serve as a catalyst. Indeed, European interests can often be better served by following a unified approach. With this aim, Eutelsat has started a detailed study of the technical, operational, economic and political aspects of a unique European direct broadcasting system which would follow a series of separate national initiatives. Eutelsat is also closely studying the development of mobile communications techniques, and the evolving need for a satellite-based land mobile service.

Eutelsat has thus fully accomplished its initial task of providing an impetus for advanced European industry. The days when the space industry was the monopoly of one single country have been forgotten - and this is true of both satellites and launchers. Eutelsat has made reliable, varied and competitive telecommunications services available to its member signatories while operating on a sound economic and financial basis. This success, as well as that of Intelsat and Inmarsat, is that of an international organization backed by governments, where the risks are shared between dozens of partners who, as both shareholders and users in the same venture, have a vested interest in leading that venture to success. Consistent political cooperation throughout the continent makes Eutelsat strategically and operationally effective - to the benefit of everyone.

The success of these organizations serves as a clear example of international cooperation which should not be placed at risk by the financial interests of private investors. Intergovernmental satellite telecommunications organizations are showing the way forward to more extensive and more developed international cooperation between counțies at many other levels. 